\title{
Comparative experimental transmission of cardiomyopathy syndrome (CMS) in Atlantic salmon Salmo salar
}

\author{
D. W. Bruno*, P. A. Noguera \\ Marine Scotland, Marine Laboratory, PO Box 101, 375 Victoria Road, Aberdeen AB11 9DB, UK
}

\begin{abstract}
Cardiomyopathy syndrome (CMS) has been recorded in wild and farmed Atlantic salmon Salmo salar. Characteristic heart lesions primarily involving the myocardium are reported in natural outbreaks with associated mortality. To date, no experimental trials have reproduced these lesions in the laboratory. The present study reports on the first successful experimental transmission of CMS in Atlantic salmon in Scotland, with full development of the histological lesions that are described for the syndrome. Tissue homogenates of CMS-infected fish indicative of mild and severe lesions from Scottish and Norwegian natural outbreaks, respectively, were injected into naïve fish, and both induced heart lesions consistent with CMS. Lesion development was earlier and progression faster in the fish group receiving the Norwegian homogenate, but equivalent in both groups by the end time point of the experiment. The study demonstrated that the reported condition for both countries is identical, as evaluated through light microscopy, and that tissue homogenates from either mild or severely affected fish contain the transmissible agent.
\end{abstract}

KEY WORDS: Cardiomyopathy syndrome · Atlantic salmon · Transmission

Resale or republication not permitted without written consent of the publisher

\section{INTRODUCTION}

Cardiomyopathy syndrome (CMS) is an economically important disease of adult Atlantic salmon Salmo salar in seawater (Brun et al. 2003). This enigmatic syndrome currently accounts for significant losses through disease in terms of tonnage (S. Murray pers. comm. 2009). The first presumptive reports of CMS occurred in the mid-1980s for farmed salmon at coastal aquaculture sites in western Norway (Amin \& Trasti 1988), but CMS has now been reported to occur in most of the salmon farming areas in Norway (Ferguson et al. 1990), as well as in wild salmon (Poppe \& Seierstad 2003). Elsewhere, CMS was documented in Atlantic salmon from the Faeroe Islands, Denmark (Poppe \& Sande 1994), from Scotland (Wood et al. 1995, Rodger \& Turnbull 2000) and also in pre-harvest salmon from Canada (Brocklebank \& Raverty 2002). The syndrome has primarily been observed in adult fish after 12 to 18 mo in seawater (Rodger \& Turnbull 2000, Brun et al. 2003); consequently, there is a significant impact on market-size fish that can die suddenly from presumptive heart failure (Brun et al. 2003).

CMS is diagnosed on the basis of histopathology, whereby a characteristic severe, chronic lesion affecting the spongiosum of the atrium and ventricle can be observed. Fish with CMS may cease feeding and swim sluggishly, developing skin haemorrhaging, raised scales and oedema (Rodger \& Turnbull 2000, Poppe \& Seierstad 2003). Typical findings at necropsy are ascitic fluid, fibrinous peritonitis and blood clots on the dorsocranial surface of the liver and surrounding the heart, or within the heart, with subsequent cardiac tamponade (Ferguson et al. 1990, Rodger \& Turnbull 2000, Poppe \& Seierstad 2003). Fish affected by the disease are, however, often in good condition, showing few clinical signs before death.

Grotmol et al. (1997) reported the detection of endotheliotropic nodavirus-like particles in heart tissue of salmon diagnosed with CMS. Positive immunolabelling of cells within the endocardium, epicardium and myocardium was observed through the use of a primary antibody against striped jack nervous necrosis virus. No 
further studies on possible causative agents have, however, been published, and, currently, the cause or causes of CMS remains unknown, and no model of the infection is available. The salmon farming industry has requested an international effort towards identifying whether an infective agent is the cause of CMS, in order to improve diagnostics, study the epidemiological basis of infection and, ultimately, improve CMS disease control strategies. This study of pathogenesis was designed to determine if CMS could be reproduced in naïve Atlantic salmon by injecting tissue homogenates taken from severely or mildly affected fish.

\section{MATERIALS AND METHODS}

Fish. The experimental Atlantic salmon Salmo salar were reared from eggs at the Marine Scotland laboratory's experimental unit at Aultbea, Ross-shire, and transported to the laboratory in Aberdeen 2 mo prior to use. Large fish were selected for this experiment (mean weight: $1.1 \mathrm{~kg}$ ) as reports indicate that CMS primarily occurs in this size group. The fish had been subject to health checks biannually since hatching, testing negative for infectious pancreatic necrosis virus (IPNV), viral haematopoietic necrosis virus (VHSV), furunculosis and bacterial kidney disease (BKD). In addition, 30 fish from the stock for this experiment were examined for salmonid alphavirus (SAV), infectious salmon anaemia virus (ISAV), IPNV and VHSV before the experiment was started, and bacterial isolation was attempted by inoculating samples onto tryptone soya agar (TSA) (Oxoid) with $2 \% \mathrm{NaCl}$, at $15^{\circ} \mathrm{C}$. Plates were examined for growth daily for $7 \mathrm{~d}$. Kidney and heart tissue were obtained from the same stock and frozen at $-80^{\circ} \mathrm{C}$ until required for injection into the control fish.

Experimental design. The Scottish homogenate was taken from 3 salmon hatched in 2003 and transferred to the sea in June 2004. Histological examination indicated that these fish had mild lesions associated with the spongiosum of the ventricle, which is consistent with CMS infection. The Norwegian tissue homogenate was taken from 3 fish hatched in 2003 and transferred to the sea between May and July 2004. The sample was collected and pooled on 15 November 2005 after histological examination indicated severe heart lesions consistent with CMS. Tissue portions (kidney and heart) from both groups were stored frozen at $-80^{\circ} \mathrm{C}$ until required.

The experimental Atlantic salmon were divided into 6 replicate groups of $30 \mathrm{fish} \mathrm{tank}^{-1}$ (a total of $180 \mathrm{fish}$ ). For each group (Scottish or Norwegian), $12 \mathrm{~g}$ of mixed kidney and heart tissue from the confirmed CMS cases described above, and similarly from control fish that were negative for CMS by light microscopy, were defrosted. Transport medium, L-15 medium 10\% newborn calf serum, penicillin-streptomycin $\left(200 \mathrm{U} \mathrm{ml}^{-1}\right)$, gentamicin (50 $\mathrm{mg} \mathrm{ml}^{-1}$ ) and polymixin B sulphate (400 $\mathrm{U} \mathrm{ml}^{-1}$ ) were added to the tissues and homogenised. The supernatant was then diluted further with transport medium to the total volume required for the inoculum. Syringes were pre-loaded with $1 \mathrm{ml}$ fish $^{-1}$ and kept cool until injection (up to $1 \mathrm{~h}$ ). A sample of each homogenate was kept for virological screening as described below.

The aquarium seawater was maintained at $10^{\circ} \mathrm{C}$ throughout the experiment and monitored continually. The fish were fed at a rate of $1 \%$ body weight of feed $\mathrm{d}^{-1}$ fish $^{-1}$ (Skretting Atlantic 500+), and each tank was provided with flow-through water at a rate of $400 \mathrm{l} \mathrm{h}^{-1}$. The procedures and experimental protocols were licensed according to current UK regulations (The Animals [Scientific Procedures] Act 1986).

Light microscopy. Following terminal anaesthesia with tricaine methane sulphonate (MS222) at $0.1 \mathrm{~g} \mathrm{l}^{-1}$, fish were sampled at 52, 143 (final date for Norwegian group) and 150 (final date for Scottish group) days post-injection (dpi), at which times the experiment was terminated. Single moribund fish were also sampled at 110 and 130 dpi.

Tissues were fixed in $10 \%$ buffered neutral formalin solution for a minimum of $24 \mathrm{~h}$, they were paraffin embedded, and sections were stained routinely with haematoxylin and eosin (H\&E). Additional sections of heart, kidney, spleen and liver were also stained with Perl's stain (Bancroft \& Stevens 2007) for haemosiderin and iron. Selected heart sections were stained for demonstration of fibrin with modified Masson's trichrome (Culling 1974) by replacing ponceau 2R stain with $1 \%$ acid fuchsin. All slides were coded, and microscopy evaluation was carried out 'blindly' when the whole study was completed, i.e. without knowledge of the group to which they belonged. Tissues were confirmed positive for CMS based on heart lesions as described by Ferguson et al. (1990) and Poppe \& Seierstad (2003). Lesion development in the atrium and ventricle was scored for severity (mild, moderate and severe) and recorded separately for the CMS-positive fish. Red and white muscle, pancreas, liver and heart were examined by light microscopy to exclude lesions attributed to alphavirus and HSMI (heart and skeletal muscle inflammation).

Virology. Homogenates were screened for SAV, IPNV, ISAV, IHNV and VHSV by tissue culture for virus isolation. To screen for VHSV and IHNV, the homogenates were inoculated onto BF-2 and FHM, respectively, and were incubated at $15^{\circ} \mathrm{C}$ for $14 \mathrm{~d}$ with sub-cultivation on Day 7. To screen for ISAV, the homogenates were inoculated onto TO (leucocyte 
line), and incubated at $15^{\circ} \mathrm{C}$ for up to $30 \mathrm{~d}$ with subcultivation on Day 14. To screen for SAV and IPNV, the homogenates were inoculated onto Chinook salmon embryo (CHSE 214), and incubated at $15^{\circ} \mathrm{C}$ for up to $42 \mathrm{~d}$ with sub-cultivation on Days 7 and 14 .

Quantitative PCR of serum samples for SAV. Blood was collected in heparinised tubes, and serum was stored frozen at $-80^{\circ} \mathrm{C}$. RNA extraction was performed using the QIAGEN MagAttract Viral M48 RNA Kit on the Q M48 BioRobot according to the manufacturer's protocol. Resultant RNA was converted into cDNA using the TaqMan Reverse Transcription Reagents kit (Applied Biosystems) as follows: $19.25 \mu$ l of total RNA was mixed in a final volume of $50 \mu$ containing the following: $1 \times \mathrm{RT}$ buffer $(25 \mathrm{mM}$ Tris- $\mathrm{HCl} \mathrm{pH} 8.3,37.5 \mathrm{mM}$ $\mathrm{KCl}), 5.5 \mathrm{mM} \mathrm{MgCl} 2,2.5 \mu \mathrm{l}$ of $50 \mu \mathrm{M}$ random hexamers, $0.5 \mathrm{mM}$ of each dNTP, $0.4 \mathrm{U}$ RNase Inhibitor and 1.25 U Multiscribe Reverse Transcriptase. The mixture was incubated at $25^{\circ} \mathrm{C}$ for $10 \mathrm{~min}, 48^{\circ} \mathrm{C}$ for $30 \mathrm{~min}$, heat inactivated at $95^{\circ} \mathrm{C}$ for $5 \mathrm{~min}$ and then stored at $-20^{\circ} \mathrm{C}$. The resultant cDNA was then amplified using a UKASaccredited assay with primers Q-nsP1 F, Q-nsP1 R and the probe Q-nsP1 P (Hodneland \& Endresen 2006). Quantitative PCR (qPCR) was performed using an ABI Prism 7000 (Applied Biosystems) under the following cycling conditions: 1 cycle of $37^{\circ} \mathrm{C}$ for $10 \mathrm{~min}, 1$ cycle of $95^{\circ} \mathrm{C}$ for $10 \mathrm{~min}$, followed by 45 cycles of $95^{\circ} \mathrm{C}$ for $15 \mathrm{~s}$ and $60^{\circ} \mathrm{C}$ for $1 \mathrm{~min}$.

A total of 46 fish across all groups died during the experiment. A pump failure at $28 \mathrm{dpi}$ resulted in the death of 13 fish (8 from 1 Scottish injected tank and the rest from a control tank). In addition, another 10 control, 10 Scottish homogenate-injected and 13 Norwegian homogenate-injected fish died during a period of $56 \mathrm{~d}$, thus reducing the total number of analysed fish to 134 .

\section{RESULTS}

\section{Bacteriology and virology}

Atlantic salmon Salmo salar sampled prior to the start of this experiment showed no evidence of bacterial infection and no histological evidence of CMS, HSMI, IPN, ISA, or alphavirus infection. Similarly the injected tissue homogenates checked by virus culture for alphavirus, ISAV and IPNV and by PCR for ISAV and alphavirus all showed negative results. Serum samples analysed by qPCR were also negative for SAV.

\section{Gross findings}

Fish sampled at scheduled time points did not show any specific external lesions that could be linked to
CMS. Of the 46 fish that died, most occurred during the night and were unsuitable for sampling; however, 2 fish were found moribund and were sampled in full. Externally, they showed mild ventral haemorrhaging of the skin, while, internally, dilatation of the atrium and sinus venosus and a few blood clots near the heart were observed. These lesions were not recorded in the control groups. Mortality started at $67 \mathrm{dpi}$, and the last dead fish was registered at $123 \mathrm{dpi}$. For an additional $27 \mathrm{~d}$, until the termination of the experiment, no further mortalities were recorded.

\section{Histopathology}

Initial results from blind examination were recorded in an Excel file, and then records and sections were re-organised according to treatment group and sampling date, to enable interpretation and analysis of the histopathological changes. Both injected groups recorded heart lesions at $52 \mathrm{dpi}$, but with different levels of severity and tissue involvement. In the Scottish injected group, $20 \%$ of the fish sampled showed small foci of mild endocardial proliferation in the atrium, namely a thickened endocardium due to a combination of hyperplasia and hypertrophy of endothelial cells (Fig. 1A). At this time point, 100\% of the fish sampled from the Norwegian group showed widespread changes compatible with early CMS in both atrium and ventricle. Typical histopathological changes included diffuse endocardial proliferation and subendocardial mononuclear infiltration (monocytes, macrophages) and, occasionally, neutrophils. These changes were mild and primarily noted in the atrium of the Scottish group, but widespread and also involving the ventricular spongiosum of the Norwegian group (Fig. 1B). Myocyte disarray was particularly noticeable in the spongiosum and atrium of the Norwegian group, but still largely absent in the Scottish group at 52 dpi. In addition, slight loss of myofibre striation and scattered hypertrophic, pleomorphic nuclei were seen in the atrium and ventricle in both groups (Fig. 1C). The large, wavy and elongated nuclei (up to $40 \mu \mathrm{m}$ ) were similar to the Anitschkowlike nuclei cells described by Ferguson et al. (2005), though lacking the wavy chromatin pattern.

At 110 dpi, a freshly moribund fish sampled from the injected Norwegian group showed extensive lesions consistent with CMS (Fig. 2), and, by 143 dpi (the final sampling for the Norwegian groups), $63 \%$ of the remaining fish had severe CMS lesions, primarily involving the ventricle, with extensive myocardial infiltration and endocardial proliferation still evident. Hypertrophic, pleomorphic and centrally located nuclei were prominent at this time point within the ventricle spon- 

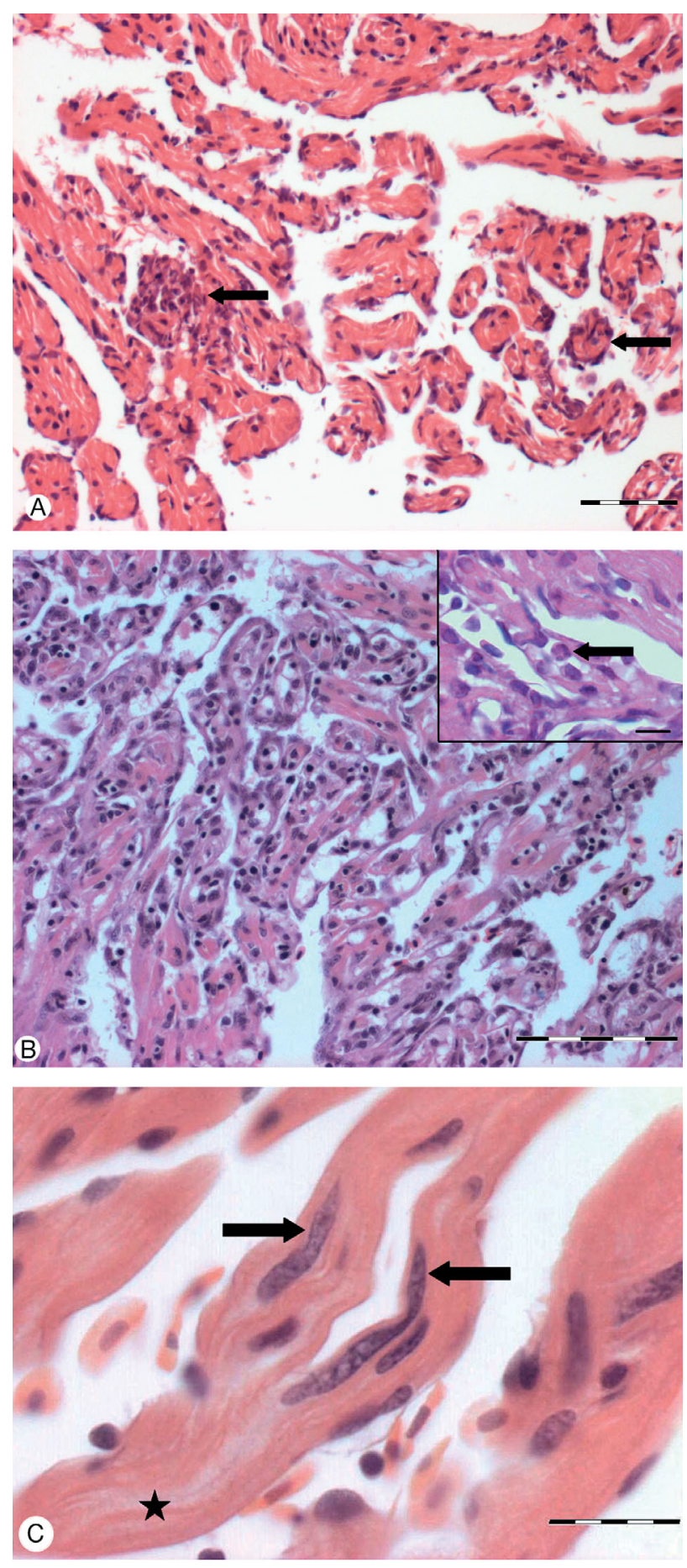

Fig. 1. Salmo salar. Cardiomyopathy syndrome in Atlantic salmon at 52 d post-injection. (A) Scottish group: focal, mild thickening of the endocardium in the atrium (arrows). (B) Norwegian group: endocardial proliferation and subendocardial infiltration in the ventricle spongiosum. Occasional neutrophils were observed (see inset). (C) Both groups: slight loss of myofibre striation $(\star)$ and scattered hypertrophic, pleomorphic nuclei (arrows). All panels haematoxylin and eosin staining; scale bars $=100 \mu \mathrm{m}(\mathrm{A}, \mathrm{B})$ and $20 \mu \mathrm{m}$ (B inset, C)

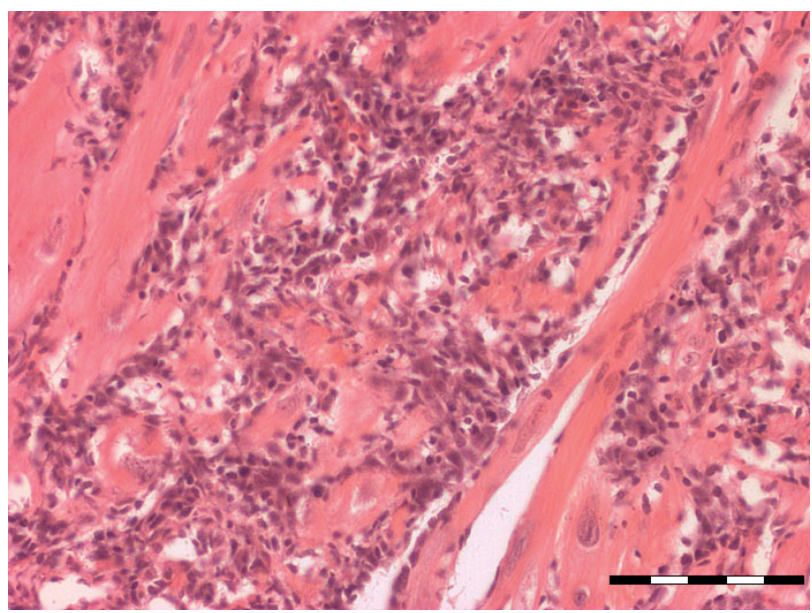

Fig. 2. Salmo salar. Cardiomyopathy syndrome in Atlantic salmon at $110 \mathrm{~d}$ post-injection. Norwegian group: severe myocardial infiltration. Haematoxylin and eosin staining; scale bar $=100 \mu \mathrm{m}$

giosum, often adjacent to areas of massive infiltration, degeneration and necrosis of the myocardium (Fig. 3A). Some fish however showed evidence of early regeneration and fibrosis within the atrium (Fig. 3B), with an overall reduction in the inflammatory response. The Scottish group at 143 dpi showed $57 \%$ of the sampled fish had moderate to severe lesions consistent with CMS (Fig. 3C), and, at 150 dpi (final sampling for the Scottish group), $75 \%$ of the remaining fish were diagnosed with widespread characteristic CMS lesions involving both the atrium and ventricle (Fig. 4). However, fish were still displaying moderate to severe infiltration and muscle degeneration, involving both the atrium and ventricle, in comparison to the $143 \mathrm{dpi}$ terminal sampling of the Norwegian group. Focal to diffuse epicarditis ranging from mild to moderate was recorded in both injected groups throughout the experiment, and, occasionally, although mild, was also observed in control fish. Thrombi in the heart chambers were infrequent, and multinucleated giant cells, melanin accumulation, or melanisation as previously described by Ferguson et al. (2005) were not observed during this experiment.

The control fish did not show lesions consistent with any of those reported for CMS. Additional observations in other tissues from the homogenate-injected fish included mild to moderate congestion within the ellipsoids in some spleen sections and an increase in haemosiderin from the CMS groups at $143 \mathrm{dpi}$. At the same time, a mild focal but spreading necrosis in the hepatic parenchyma was also noted.

Overall, both groups developed CMS lesions, though on different time scales. At the end of the experiment, heart-specific CMS lesions were recorded in 57 and 

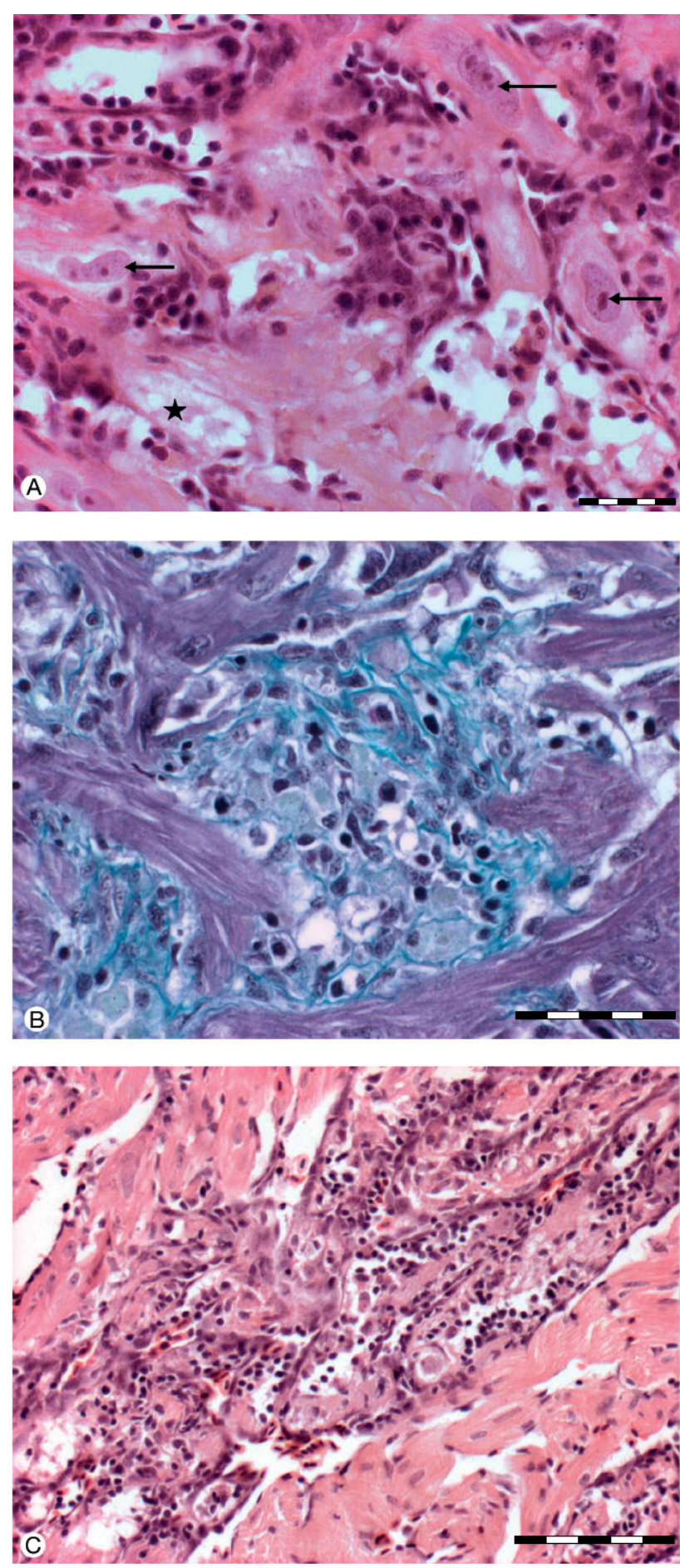

Fig. 3. Salmo salar. Cardiomyopathy syndrome in Atlantic salmon at 143 d post-injection. (A) Norwegian group: hypertrophic, pleomorphic centrally located nuclei (arrows) within the spongiosum myocardium adjacent to areas of myocardium infiltration, degeneration and necrosis $(\star)$. Haematoxylin and eosin (H\&E) staining. (B) Norwegian group: evidence of reparative processes (fibrosis) in the ventricle. Masson's trichrome. (C) Scottish group: focal but severe characteristic lesions developing in the ventricle. H\&E staining; scale bars $=50 \mu \mathrm{m}(\mathrm{A}, \mathrm{B})$ and $100 \mu \mathrm{m}(\mathrm{C})$

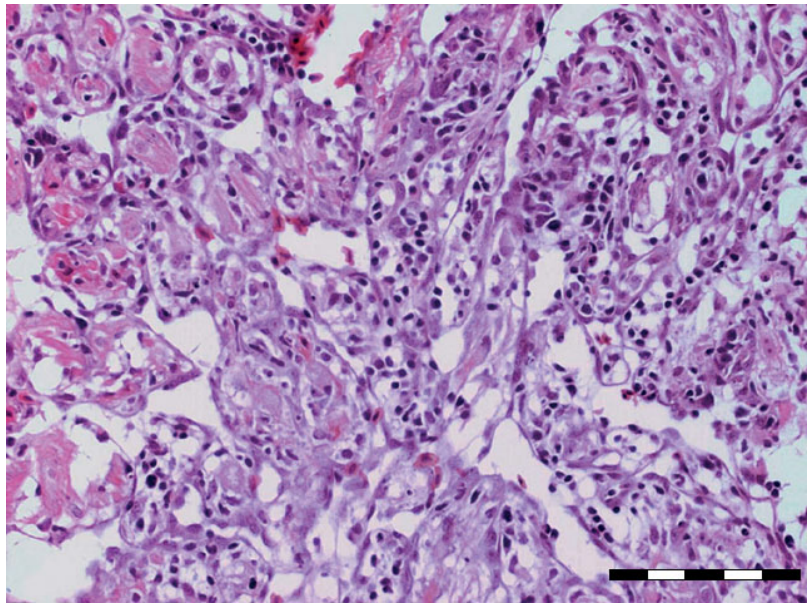

Fig. 4. Salmo salar. Cardiomyopathy syndrome in Atlantic salmon at 150 d post-injection. Scottish group: severe, widespread, myocardial infiltration and degeneration involving the ventricle. Haematoxylin and eosin staining; scale bar $=100 \mu \mathrm{m}$

$60 \%$ of the sampled Scottish and Norwegian infected groups, respectively. CMS lesions in the Norwegian group were evident prior to those in the Scottish fish and showed lesions consistent with CMS by $52 \mathrm{dpi}$. Severe CMS was recorded at $110 \mathrm{dpi}$, and regenerative processes were evident by $143 \mathrm{dpi}$. CMS in the Scottish group showed mild changes by $52 \mathrm{dpi}$, but did not reach maximum severity until $150 \mathrm{dpi}$.

\section{DISCUSSION}

Cardiomyopathies are heart conditions characterised by dysfunction of the myocardium. CMS is one of several diseases affecting the cardiac muscle of Atlantic salmon Salmo salar (Ferguson et al. 1990, Poppe \& Seierstad 2003, Poppe et al. 2007). In the current study, the condition was fully reproduced by injection of Scottish and Norwegian homogenates; hence, the frozen tissues proved to be infective, indicating that the causative agent is present in both mildly or severely affected fish and is able to survive at least 1 freeze/thaw cycle at $-80^{\circ} \mathrm{C}$. The CMSassociated lesions described in the current study parallel those published for natural infections of wild and farmed salmon (Ferguson et al. 1990, Poppe \& Seierstad 2003), including endocarditis, infiltration, muscle degeneration, necrosis and finally fibrosis. These findings were supported by the removal of bias during the initial reading of the slides, the absence of similar lesions in the control groups and the fact that CMS lesions were reproduced from both the Scottish and Norwegian homogenates. Furthermore, all of the fish tested prior to the experiment were free of specific 
pathogens and the testing of the injected tissue homogenate was free of known salmonid viral agents. It is noteworthy that very early changes described in the atrium of challenged fish, including diffuse proliferation and hypertrophy of individual endocardial cells, were not previously attributed directly to CMS. We now believe these to be indicative of early morphological changes due to the syndrome.

The progression of the observed lesions in both infected groups demonstrated that lesions initially occur in the atrium, with subsequent progression to the ventricle. Furthermore, the fish injected with the Norwegian homogenate developed lesions far earlier than the Scottish group. Lesions in the atrium developed at a similar rate in both groups, though obviously displaced in time; hence, throughout the study, at the same point in time lesions were always more widespread in the Norwegian group. However, towards the end of the experiment, heart lesions in both groups reached equivalent levels of severity. It was concluded that the difference in the onset of the disease may reflect different levels of 'infectious agent' present in the original tissue homogenate; if this is true, it would indicate that severely affected fish harbour (and eventually shed) higher amounts of the infectious agent compared to fish with early lesions. However, this result could also reflect different strains of an infectious agent, with different levels of pathogenicity. The specific cause for the destruction of the cardiomyocytes in CMS-infected fish is, at present, unknown, but may be associated with the severe and extensive inflammatory response affecting the myo- and endocardium, which can occur through virus-mediated myocarditis, leading to lysis. Such a progression, for example, has been reported in association with Coxsackievirus B in man, resulting in myocyte damage and cardiovascular disease (MacArthur et al. 1984, Horwitz et al. 2000).

Hypertrophic and pleomorphic cardiac myocyte nuclei were recorded in the ventricle spongiosum and atrium, and are believed to represent a compensatory reaction to a failing heart, as suggested by Ferguson et al. (1990). The long, wavy and elongated nuclei seen in some fish from both injected groups resembled Anitschkow myocytes, which are believed to be pathognomonic of acute rheumatic carditis in man (Guilherme et al. 2004). Ferguson et al. (2005) suggested that the Anitschkow-like nuclei were linked with the myocardial repair or regeneration of the heart and skeletal muscle inflammation-like condition in Atlantic salmon. In the present study, however, this cell type was observed throughout the experiment, but primarily during the early heart lesions associated with CMS. The pathological changes in the heart muscle of CMSinfected fish could result in an increase in cardiac workload, inducing mechanical stress, as reported fol- lowing continued damage to the stressed heart and haemodynamic overload in humans, which may well induce the critical transition from compensatory hypertrophy to decompensated heart failure (Diwan \& Dorn 2007). Only a few thrombi were noted in the heart chamber in the experimental fish, which Ferguson et al. (1990) suggested was common in severely affected salmon, and we expect that, with longer periods of experimental observation, an increase in this lesion type would be found.

CMS-associated mortality is associated with presumptive heart failure, which suggests that the high metabolic activity and increased oxygen extraction required by the subendocardium would be significant for large, fast-growing fish. However, small fish generally consume more oxygen than larger fish, on a unit weight basis (Forsberg 1994); hence, the apparent absence of CMS in post-smolts is unlikely to be explained on the basis of oxygen demand by heart tissue alone. However, as a chronically developing disease, it is not known whether smolts might be infected but do not develop obvious lesions until they are grown, when they are no longer able to cope with the dysfunctional heart. Although there is increasing evidence that intensively reared fish significantly alter some aspects of their cardiac anatomy (Santer et al. 1983, Farrell 2002, Poppe et al. 2007) and physiology (McDonald et al. 1998), the occurrence of CMS in both wild and farmed fish indicates that aquaculture constraints are not the primary factors causing this syndrome.

Fish from the injected groups showed a mild to moderate multifocal hepatic necrosis consistent with reports for natural outbreaks (Grotmol et al. 1997, Rodger \& Turnbull 2000). This might be attributed to a circulatory disturbance or reduced cardiac output, leading to hypoxia, and might be consistent with the presence of ascites recorded in natural infections. Anaemia is not reported as a specific feature of CMS, but the hepatocyte necrosis noted in the present study and the presence of haemosiderin within the spleen parenchyma suggest that there is some level of destruction of erythrocytes. An increase in fibrosis was associated with resolving focal lesions within the atrium and ventricle during cardiomyocyte regeneration and similar to that reported in the zebra fish Danio rerio following ventricular resection (Ross et al. 2002). In mammals, reparative fibrosis subsequent to myocardial cell necrosis is a well-described process (see Weber 1989), and acute myocarditis can lead to healing with fibrosis and cardiomyocyte hypotrophy (Billingham \& Tazelaar 1986, Hasumi et al. 1986, Larsson et al. 1999).

In addition to CMS, since the mid-1980s, other significant heart-associated pathologies have been reported in farmed fish, including subendocardial fibro- 
elastosis (Amin \& Poppe 1989), haemorrhagic smolt syndrome (HSS) (Nylund et al. 2003), HSMI (Kongtorp et al. 2004a,b), myocardial necrosis (Poppe et al. 2007) and infections attributed to a SAV (McLoughlin \& Graham 2007, Murphy et al. 2006). Of these, only CMS has been reported from wild salmonids (Poppe \& Seierstad 2003). CMS, SAV and HSMI present overlapping histopathology, and this has led to discussion regarding these conditions as representing separate diseases with distinct aetiologies or new conditions or variants of existing diseases (Kongtorp et al. 2004a). From our present knowledge CMS, HSMI and HSS represent distinct syndromes, although interestingly Ferguson et al. (2005) reported presumptive HSMI from farmed salmon in Scotland, with heart lesions that were similar to those described for CMS, but also showing an increased inflammatory reaction and an increase in multinucleate 'nests' within the myocytes, which are not reported for CMS.

For a differential diagnosis, CMS and HSMI are characterised by mononuclear infiltration affecting the myocardium and endocardium (Ferguson et al. 1990, Kongtorp et al. 2004b), and HSMI and alphavirus infection both show severe myocarditis and myocardial necrosis, but in association with skeletal muscle involvement (McLoughlin et al. 2002, Kongtorp et al. 2004b). However, in CMS, the myocardial fibres are gradually replaced by inflammatory cells, as noted in the present study, and are only rarely recorded for HSMI (Kongtorp et al. 2004a,b). Data from those studies (op. cit.) and those published for CMS, HSMI and alphavirus infections (Rodger \& Turnbull 2000, Ferguson et al. 2005, Kongtorp et al. 2004a,b, McLoughlin \& Graham 2007) indicate that histological separation is possible for typical cases. However, the chronic nature of CMS, as reported in the present study, and HSMI (Kongtorp et al. 2006) would suggest that fish can experience concurrent or overlapping infections, so that early clinical signs and the cell types involved become important for diagnosis at a stage when not all the lesions characteristic of each disease are present.

Further work is required to establish the infectious agent for CMS. Poppe \& Seierstad (2003) postulated a possible viral aetiology due to the occurrence of CMS in wild Atlantic salmon, while the occasional observations of intranuclear inclusion bodies were also postulated as indication of viral infection by Amin \& Trasti (1988). However, the only published paper on a proposed viral aetiology of CMS was presented by Grotmol et al. (1997), in which the cardiac atrial and ventricular trabeculae were reported to display positive immunohistochemistry against a nodavirus, although a causal relationship between the viral particles and CMS was not established. The antibiotics present in the tissue culture medium used to homogenise the tis- sues prior to injection in the current study would have been expected to inhibit bacteria during the estimated contact time of from 1 to $2 \mathrm{~h}$, suggesting that a bacterium is not involved, as reported by Amin \& Trasti (1988). Reports to date (Rodger \& Turnbull 2000, Brun et al. 2003) note that CMS occurs in fish that are entering or are in their second year of seawater production, and Saunders et al. (1992) noted coronary heart lesions increased with rapid growth at sea. However, as noted above, cardiomyopathy can result from numerous causes, including congenital defects, acute or chronic infections, connective tissue disorders, deformities, nutritional deficiencies and autoimmunity (Amin \& Poppe 1989, Poppe \& Taksdal 2000, Nylund et al. 2003, Poppe et al. 2003, 2007). Furthermore, there may well be other influencing factors; for example, Flysand et al. (1992) noted that salmon accumulate adrenaline in atrial tissue during periods of stress, and, in high amounts, this is reported to be cardiotoxic (Carlsten et al. 1983).

The current study has established that kidney/heart tissues of natural CMS outbreaks contained infective material, which reproduced CMS lesions in naïve fish. Moreover, similar results to those reported here have been recently obtained in a study using smaller fish in Norway (Fritsvold et al. 2009). The injection of homogenates from Scotland and Norway groups provided clear evidence that a transmissible agent was present in both inoculated homogenates, those taken from fish with mild (i.e. Scotland) as well as severe (i.e. Norway) CMS lesions. Furthermore, the results also confirm the chronic development of CMS. This is important to our understanding of the disease, and to the development of appropriate management practices to hinder its transmission.

Acknowledgements. The authors thank A. Turnbull for helping with the histology processing, J. Black for qPCR testing of the serum samples, K. Lester for processing the viral samples and U. McCarthy for helpful discussion. We are also very grateful to R. Kongtorp for providing the infected tissue from Norwegian fish.

\section{LITERATURE CITED}

Amin AB, Poppe TT (1989) Subendocardial fibroelastosis in Atlantic salmon. A case report. Bull Eur Assoc Fish Pathol 8:70-71

Amin AB, Trasti J (1988) Endomyocarditis in Atlantic salmon in Norwegian sea farms. Bull Eur Assoc Fish Pathol 8: 70-71

Bancroft JD, Stevens A (2007) Theory and practice of histological techniques, 6th edn. Churchill Livingstone, London

> Billingham ME, Tazelaar HD (1986) The morphological progression of viral myocarditis. Postgrad Med J 62:581-584

> Brocklebank J, Raverty S (2002) Sudden mortality caused by cardiac deformities following screening of preharvest 
farmed Atlantic salmon (Salmo salar) and by cardiomyopathy of postintraperitoneally vaccinated Atlantic salmon parr in British Columbia. Can Vet J 43:129-130

Brun E, Poppe T, Skrudland A, Jarp J (2003) Cardiomyopathy syndrome in farmed Atlantic salmon Salmo salar: occurrence and direct financial losses for Norwegian aquaculture. Dis Aquat Org 56:241-247

Carlsten A, Poupa O, Volkmann R (1983) Cardiac lesions in poikilotherms by catecholamines. Comp Biochem Physiol A 76:567-581

Culling CFA (1974) Handbook of histochemical techniques, 3rd edn. Butterworths \& Co., London

> Diwan A, Dorn GW (2007) Decompensation of cardiac hypertrophy: cellular mechanism and novel therapeutic target. Physiology (Bethesda) 22:56-64

Farrell AP (2002) Coronary arteriosclerosis in salmon, growing old or growing fast? Comp Biochem Physiol A 132: 723-735

Ferguson HW, Poppe T, Speare DJ (1990) Cardiomyopathy in farmed Norwegian salmon. Dis Aquat Org 8:225-231

> Ferguson HW, Kongtorp RT, Taksdal T, Graham D, Falk K (2005) An outbreak of disease resembling heart and skeletal muscle inflammation in Scottish farmed salmon, Salmo salar L., with observations on myocardial regeneration. J Fish Dis 28:119-123

Flysand R, Ask JA, Serck-Hanssen G, Helle KB (1992) Plasma catecholamines and accumulation of adrenaline in the atrial cardiac tissue of aquaculture Atlantic salmon (Salmo salar). J Fish Biol 41:103-111

Forsberg OI (1994) Modelling oxygen consumption rates of post-smolt Atlantic salmon in commercial scale landbased farms. Aquac Int 2:180-196

Fritsvold C, Kongtorp RT, Taksdal T, Ørpetveit I, Heum M, Poppe TT (2009) Experimental transmission of cardiomyopathy syndrome (CMS) in Atlantic salmon Salmo salar. Dis Aquat Org 87:225-234

> Grotmol S, Totland GK, Kryvi H (1997) Detection of a nodavirus-like agent in heart tissue from reared Atlantic salmon Salmo salar suffering from cardiac myopathy syndrome (CMS). Dis Aquat Org 29:79-84

Guilherme L, Cury P, Demarchi LMF, Coelho V and others (2004) Rheumatic heart disease. Proinflammatory cytokines play a role in the progression and maintenance of valvular lesions. Am J Pathol 165:1583-1591

Hasumi M, Sekiguchi M, Yu ZX, Hirosawa K, Hiroe M (1986) Analysis of histologic findings in cases with dilated cardiomyopathy with special reference to formulating diagnostic criteria on the possibility of postmyocarditic change. Jpn Circ J 50:1280-1287

Hodneland K, Endresen C (2006) Sensitive and specific detection of salmonid alphavirus using real-time PCR (TaqMan). J Virol Methods 131:184-192

> Horwitz MS, La Cava A, Rodriguez E, Ilic A, Sarvetnick N (2000) Pancreatic expression of interferon-gamma protects mice from lethal coxsackievirus B3 infection and subsequent myocarditis. Nat Med 6:693-697

Kongtorp RT, Kjerstad A, Taksdal T, Guttvik A, Falk K (2004a) Heart and skeletal muscle inflammation in Atlantic salmon, Salmo salar L: a new infectious disease. J Fish Dis 27: 351-358

Kongtorp RT, Taksdal T, Lyngøy A (2004b) Pathology of heart and skeletal muscle inflammation (HSMI) in farmed Atlantic salmon Salmo salar. Dis Aquat Org 59: 217-224

Editorial responsibility: Mark Crane,

Geelong, Victoria, Australia
Kongtorp RT, Halse M, Taksdal T, Falk K (2006) Longitudinal study of a natural outbreak of heart and skeletal muscle inflammation in Atlantic salmon, Salmo salar L. J Fish Dis 29:233-244

> Larsson E, Wesslen L, Lindquist O, Baandrup U and others (1999) Sudden unexpected deaths among young Swedish orienteers - morphological changes in hearts and other organs. APMIS 107:325-336

MacArthur CGC, Tarin D, Goodwin JF, Hallidie-Smith KA (1984) The relationship of myocarditis to dilated cardiomyopathy. Eur Heart J 5:1023-1035

> McDonald DG, Milligan CL, McFarland WJ, Croke S and others (1998) Condition and performance of juvenile Atlantic salmon (Salmo salar), effects of rearing practices on hatchery fish and comparison with wild fish. Can J Fish Aquat Sci 55:1208-1219

McLoughlin MF, Graham DA (2007) Alphavirus infections in salmonids - a review. J Fish Dis 30:511-531

McLoughlin MF, Nelson RN, McCormick JI, Rowley HM, Bryson DB (2002) Clinical and histopathological features of naturally occurring pancreas disease in farmed Atlantic salmon, Salmo salar L. J Fish Dis 25:33-43

> Murphy TM, Rodger HD, Drinan EM, Gannon F, Kruse P, Worting W (2006) The sequential pathology of pancreas disease in Atlantic salmon farms in Ireland. J Fish Dis 15: 401-408

Nylund A, Plarre H, Hodneland K, Devold M and others (2003) Haemorrhagic smolt syndrome (HSS) in Norway: pathology and associated virus-like particles. Dis Aquat Org 54:15-27

Poppe TT, Sande RD (1994) Cardiomyopathy in farmed Atlantic salmon: a review, introducing an ultrasound technique for clinical examination. Norwegian School of Veterinary Science, Oslo

Poppe TT, Seierstad SL (2003) First description of cardiomyopathy syndrome (CMS)-related lesions in wild Atlantic salmon Salmo salar in Norway. Dis Aquat Org 56: 87-88

Poppe TT, Taksdal T (2000) Ventricular hypoplasia in farmed Atlantic salmon Salmo salar. Dis Aquat Org 42:35-40

Poppe TT, Johansen R, Gunnes G, Tørud B (2003) Heart morphology in wild and farmed Atlantic salmon Salmo salar and rainbow trout Oncorhynchus mykiss. Dis Aquat Org 57:103-108

Poppe TT, Taksdal T, Bergtun PH (2007) Suspected myocardial necrosis in farmed Atlantic salmon, Salmo salar L.: a field case. J Fish Dis 30:615-620

> Rodger H, Turnbull T (2000) Cardiomyopathy syndrome in farmed Scottish salmon. Vet Rec 146:500-501

Ross KD, Wilson LG, Keating MT (2002) Heart regeneration in zebrafish. Science 13:2188-2190

Santer RM, Greer Walker M, Emerson L, Witthames PR (1983) On the morphology of the heart ventricle in marine teleost fish (Teleostei). Comp Biochem Physiol A 76:453-457

Saunders RL, Farrell AP, Knox DE (1992) Progression of coronary arterial lesions in Atlantic salmon (Salmo salar) as a function of growth rate. Can J Fish Aquat Sci 49:878-884

Weber KT (1989) Cardiac interstitium in health and disease: the fibrillar collagen network. J Am Coll Cardiol 13: $1637-1652$

Wood BP, Bruno DW, Hastings TS (1995) Cardiomyopathy in farmed Atlantic salmon, Salmo salar, in Scotland. In: Proc 7th Int Conf Fish and Shellfish Diseases. European Association of Fish Pathologists, Palma, p 20 (poster)

Submitted: May 19, 2009; Accepted: August 13, 2009

Proofs received from author(s): November 22, 2009 